\title{
Foraging performance of juvenile Atlantic cod Gadus morhua and profitability of coastal habitats
}

\author{
Anders Persson*, Peter Ljungberg, Magnus Andersson, Elin Götzman, \\ P. Anders Nilsson
}

Department of Biology, Aquatic Ecology, Lund University, Ecology Building, 22362 Lund, Sweden

\begin{abstract}
Overfishing and eutrophication affects coastal communities worldwide, leading to dwindling fish stocks and deteriorated habitats. Hence, attempts to rebuild overfished stocks to past fish productivities need to account for functional relations between habitat types and fish performance. Here we quantified resource availability, foraging performance, and anti-predator behavior of juvenile Atlantic cod Gadus morhua (hereafter 'cod') to assess the costs and benefits associated with different coastal habitats. In the laboratory, cod foraged more efficiently in sand habitats compared to the structurally more complex habitats of eelgrass Zostera marina and the canopy forming bladderwrack Fucus vesiculosus. Presence of chemical cues from a cannibal reduced cod consumption rates in all habitats, but most strongly in the sand habitat. Field observations in the 3 habitats showed highest resource density in the bladderwrack habitat and lowest in the sand habitat, irrespective of season. Habitat profitability, calculated by combining data from field estimates of prey density and experimental quantifications of foraging performance, revealed the bladderwrack habitat to be the most profitable, independent of season. The difference in profitability between the complex habitats was relatively small, suggesting that cod in the field contributed to drive habitat profitability towards equalization. The results strengthen the view that the ongoing loss of seagrass and macroalgae habitats may have significant ramifications for juvenile cod performance, which ultimately may lower the productivity of entire stocks. Consequently, future and ongoing rebuilding of commercial fish stocks should revise the expectations of stock productivity (and hence harvesting intensity) accordingly.
\end{abstract}

KEY WORDS: Cod · Habitat choice - Macroinvertebrates - Functional response - Seagrass · Bladderwrack $\cdot$ Fucus vesicolosus $\cdot$ Zostera marina

\section{INTRODUCTION}

Overfishing is currently a major threat to the biodiversity and function of marine environments (Brooks et al. 2002, Pauly et al. 2002, Frank et al. 2005). This has led to the establishment of rebuilding management plans with the aim to reduce fisheries mortality towards sustainable levels. Such management plans rest on the scientific foundation that decreased fisheries mortality will increase the productivity of stocks towards historic levels. How- ever, recent studies illuminate how changes in the environment may interact with harvesting to promote a stock collapse or how it can counteract stock recovery (Eero et al. 2011, Lambert 2011). For example, coastal environments have often been dramatically degraded concurrently with overexploitation (Jackson et al. 2001, Lotze et al. 2006, Waycott et al. 2009). Environmental change can hereby prevent rebuilding attempts that solely mitigate the exploitation of fish stocks from achieving historic levels of fish productivity. 
One environmental change, especially in coastal areas, is habitat deterioration driven by eutrophication (Cloern 2001). Coastal environments are identified as being among the most productive habitats and serve as important nursery grounds for many aquatic species (Gibson 1994, Beck et al. 2001, Pauly et al. 2002). However, eutrophication alters the physical and biological properties by favoring filamentous algae and bare substrate over macrovegetation. Studies worldwide indicate up to $60 \%$ reduction in seagrass coverage since the 1980s (Short \& Wyllie-Echeverria 1996, Baden et al. 2003, Orth et al. 2006, Waycott et al. 2009), and a similar decline has been found for canopy-forming macroalgae (Kautsky et al. 1986, Eriksson et al. 1998, 2002). Reduced coverage and increased fragmentation creates a negative loop as resuspension of bare sediment increases turbidity and light extinction, leading to further degradation of macrovegetation (Pihl et al. 2006, Rönnbäck et al. 2007). Altered vegetation composition affects the structure of many coastal communities, including reductions of benthic invertebrates that are food for many juvenile fish (Vogt \& Schramm 1991, Orth et al. 2006, Pihl et al. 2006, Wikström \& Kautsky 2007). Hence, eutrophication causes both structural changes in the foraging environment and compositional changes of benthic invertebrates that affect the predator-prey relationship between fish and their benthic prey (Isaksson et al. 1994). As a consequence, it is essential to evaluate how environmental change has affected fish foraging possibilities to make realistic predictions of the future development of marine fish stocks. A detailed knowledge about habitat-dependent foraging performance and resource densities constitutes a basis for such evaluation.

The aim of this paper was to assess juvenile Atlantic cod Gadus morhua (hereafter referred to as 'cod') responses to habitat changes in coastal areas. Cod spend their first months of life in pelagic environments feeding on zooplankton. When reaching a sufficient size (approximately $5 \mathrm{~cm}$ ), cod become benthivorous and commonly forage on various benthic crustaceans associated with vegetated habitats (Hüssy et al. 1997). As cod grow in size, the proportion of fish such as herring and sprat in their diet increases. Coastal environments are hence particularly important habitats for juvenile cod up to an age of 3 to 4 yr. Furthermore, density-dependent interactions during the juvenile phase have been identified as important processes in statistical models of stock dynamics (Bjørnstad et al. 1999) and in field observations of growth and survival of newly settled juvenile cod (Tupper \& Boutilier 1995). Here we thus focused on the benthivorous stage of juvenile cod, aiming to provide a quantitative analysis of costs and benefits associated with different habitats, and thereby approach the underlying processes behind habitat choice and quality for cod. Moreover, due to the trophic importance of cod, population effects on cod will likely cascade to lower trophic levels (Hansson et al. 2007, Österblom et al. 2007, Casini et al. 2009, Fauchald 2010), ultimately altering the functioning of the entire ecosystem (Eriksson et al. 2009).

In the field we first quantified resource densities in 3 different habitats common in temperate coastal environments; sand, eelgrass Zostera marina, and the brown alga bladderwrack Fucus vesiculosus. In laboratory experiments, we then quantified the performance of juvenile cod when foraging in these habitats. The 3 habitats provide cod with different levels of resources, but also different possibilities for shelter from predators. We performed the experiments both with and without chemical cues from a cannibalistic cod to quantify the cost of perceived predation risk through lost foraging opportunity. Finally, we combined the results from the field estimates of resource densities and the foraging experiments to quantify the profitability, in terms of energetic intake rates, of each habitat from the standpoint of juvenile cod. Hence, this approach focuses on the processes generating habitat choices rather than trying to explain some specific choices observed in the field. We expected to find that cod, being an actively searching predator, would show a higher foraging efficiency in open habitats compared to structurally more complex habitats. Counteracting this, structurally more complex habitats provide cod with higher resource densities and better protection from predators. Hence, altering the relative distribution of the habitat types may have significant ramifications on juvenile growth and survival, and ultimately on cod population dynamics.

\section{MATERIALS AND METHODS}

\section{Foraging performance in Atlantic cod}

The colonization of coastal environments by juvenile cod is dependent on water temperature and individual size. The experimental part of our study was performed with similar-sized cod representing $1 \mathrm{yr}$ old fish, which should be susceptible to cannibalism by older ( 3 to 4 yr) conspecifics. Cod for experiments were caught with fyke nets at 2 to $5 \mathrm{~m}$ depth in the 
Sound, Western Baltic Sea $\left(55^{\circ} 56^{\prime} \mathrm{N}, 1^{\circ} 46^{\prime} \mathrm{E}\right)$ between February and April 2009. Eight cod were held individually in $150 \mathrm{l}$ tanks, with climate conditions resembling spring or autumn field conditions (range 8 to $9^{\circ} \mathrm{C}, 10$ to $15 \%$ salinity, light:dark cycle 12:12 h). The first experiment tested the effects of prey type, habitat type, and prey density on the foraging performance of the cod. Three different prey types were netted in shallow water and used as prey; opossum shrimp Neomysis integer (mean \pm SD total length, TL: $13.0 \pm 2.0 \mathrm{~mm}$ ), brown shrimp Crangon crangon (TL: $40 \pm 5 \mathrm{~mm}$ ), and grass shrimp Palaemon elegans (TL: $35 \pm 5 \mathrm{~mm}$ ). Experiments were performed in 3 different habitats: sand, eelgrass, or bladderwrack. Eelgrass habitat was simulated using green, $5 \mathrm{~mm}$ wide ribbon at a shoot density resembling the field site (514 shoots $\mathrm{m}^{-2}$; Olsson 2005) whereas natural bladderwrack from the Sound was used. All habitat types contained sand on the aquarium bottom. Experiments were performed at 5 initial prey densities ( 12 to 430 prey $\mathrm{m}^{-2}$ ) for each prey and habitat type combination, covering the range of natural densities observed at the site of field survey (brown and grass shrimp $<100$ ind. $\mathrm{m}^{-2}$, small crustaceans such as opossum shrimp $<500$ ind. $\mathrm{m}^{-2}$ ). Each cod participated in all treatment combinations, yielding a total of 45 experiments per fish. Individual cod order of exposure to habitat types and prey densities was randomized to prevent effects of time in the experiment on factorial effects. Prior to experiments, cod were starved and acclimatized in their new habitat for $48 \mathrm{~h}$. Cod foraging was visually observed, and the time between the first and the fifth prey consumed was recorded.

To quantify the habitat- and prey-specific foraging capacities of cod, we assumed that consumption rate of prey $i$ in habitat $j\left(C_{i j}\right)$ depended on prey density $\left(N_{i j}\right)$ according to a type II functional response (Holling 1959):

$$
C_{i j}=\frac{a_{i j} \times N_{i j}}{1+a_{i j} \times h_{i j} \times N_{i j}}
$$

where $a_{i j}$ and $h_{i j}$ are prey- and habitat-specific attack rates and handling times, respectively, that were estimated by non-linear least square regression. Foraging in heterogeneous habitats, which provide prey with refuges from predation, may lead to a type III functional response because search rate may not scale linearly with prey density. Therefore, we also tested a type III model where an additional parameter, $k$, was introduced to scale the density dependence $\left(N^{k}\right)$ of intake rates. The sums of squares were larger or $<5 \%$ lower with a type III model compared to a type II, i.e. a type III model generally did not improve the model fit to the data. Since the type III model includes an additional parameter, we chose to apply the type II model for all treatment combinations to facilitate comparisons of parameters across habitat and prey types.

The second experiment tested the effects of prey density, habitat type, and presence or absence of a cannibal on foraging performance of $1 \mathrm{yr}$ old cod. One adult and potentially cannibalistic cod $(60 \mathrm{~cm}$, $4 \mathrm{yr}$ ) was fed 3 live $1 \mathrm{yr}$ old cod (total length 15 to $20 \mathrm{~cm}$ ) and moved to a non-circulating but wellaerated tank containing $100 \mathrm{l}$ fresh saltwater (see Mathis \& Smith 1993 for methods). After 48 h, cue water was collected and frozen until being used in experiments. Frozen cue maintains its effect for approximately 2 mo (Pettersson et al. 2000), and in the present experiments, cue was used within $20 \mathrm{~d}$. The experimental setup and procedure was similar to the first foraging-performance experiment, except that only 1 prey type (Neomysis integer) and 2 prey densities (40 and 160 ind. $\mathrm{m}^{-2}$ ) were used, resulting in a total of 6 treatment combinations for each cod. Experiments started by adding $250 \mathrm{ml}$ of cue water, an amount sufficient to elicit a behavioral response (Pettersson et al. 2000, P. Ljungberg unpubl. data), and prey to the tanks. The time between first and fifth prey consumed was recorded.

\section{Prey density and habitat profitability}

The field surveys of prey were performed in the Western Baltic Sea (ICES subdivision 23; 56 $12^{\circ} \mathrm{N}$, $12^{\circ} 33^{\prime} \mathrm{E}_{;} 56^{\circ} 07^{\prime} \mathrm{N}, 12^{\circ} 36^{\prime} \mathrm{E}_{;} 55^{\circ} 56^{\prime} \mathrm{N}, 12^{\circ} 47^{\prime} ; 5^{\circ} 46^{\prime}$, $\left.12^{\circ} 54^{\prime} \mathrm{E}\right)$, where all 3 habitat types occur naturally and are abundant. In the Baltic Sea, high summer temperature may restrict the use of shallow, coastal environments by cod to the period between autumn and spring. We therefore sampled resource densities both in spring (April 2009) and in autumn (September 2008) when the temperature was suitable to cod to assess the effects of season on habitat profitability of the different habitats.

Three different habitat types (sand, eelgrass, and bladderwrack) were sampled for mobile epifauna at each of 4 sites. The average depth was $2.4 \mathrm{~m}$, with a maximum and minimum depth of 4.0 and $1.2 \mathrm{~m}$. Samples were collected by scuba diving using net bags to obtain quantitative data. Each net bag had a closable opening with an area of $0.07 \mathrm{~m}^{2}$, a height of $1.0 \mathrm{~m}$, and $1.0 \mathrm{~mm}$ mesh size. At each of the 4 sites, 5 bag samples were taken randomly within each of the 3 
habitat types. A sample was taken by pulling the net bag over the vegetation until it reached the substrate. Before closing the bag, eelgrass or bladderwrack were carefully cut off with a knife, and plants and organisms were sampled together. Samples were individually emptied into plastic bags on board the boat and frozen until analysis. In the laboratory, epifauna was identified to taxonomic group, weighed, and later converted to energy content. For the sake of this study, mobile epifauna was divided into 2 size groups (individual wet weight $<0.1 \mathrm{~g}$ and $>0.1 \mathrm{~g}$ ).

We used the parameters derived from Eq. (1) to quantify the habitat profitability in the field by assuming that intake rate is a proxy for habitat profitability to cod. In these calculations, we used the field estimates of habitat-specific prey densities. The most important prey in stomachs of small cod in this area are various species of crustaceans (P. Ljungberg unpubl. data). Prey size composition is an important determinant of foraging capacity in fish, and hence in our calculations, we distinguished between large (>0.1 g) and small $(<0.1 \mathrm{~g})$ crustaceans according to their clearly bimodal size distribution in the field. To calculate total intake rates in cod, we therefore used a functional response model developed for several prey types (modified from Fryxell \& Lundberg 1998):

$$
C_{i j}=\frac{\sum a_{i j} \times N_{i j}}{1+\sum a_{i j} \times h_{i j} \times N_{i j}}
$$

In each habitat, we calculated the added consumption of both small and large crustaceans. As model species for small crustaceans, we used the parameters derived for Neomysis integer in all habitats. The choice of large model species was based on which of Crangon crangon and Palaemon elegans, respectively, that was most abundant in each habitat. This resulted in the use of $C$. crangon as the model species in sand and $P$. elegans in both eelgrass and bladderwrack habitats.

\section{Statistical analysis}

The effects of habitat type (sand, eelgrass, or bladderwrack) and season (spring and autumn) on densities (log normal) of small and large prey in field sampling were tested using a randomized block (rb) multivariate analysis of variance (MANOVA) with site $(\mathrm{n}=4)$ as a blocking factor. The effects of predator cue (with and without), prey density (low or high), and habitat type (sand, eelgrass, or macroalgae) on consumption rates in the laboratory were tested using an rbANOVA with individual $\operatorname{cod}(\mathrm{n}=8)$ as the blocking factor. All experimental cod participated in all treatment combinations. Including individual identities as a blocking factor allows for evaluation of factor effects in spite of possible different levels of effects among individuals, as well as adjusting the degrees of freedom according to the repeated use of individuals (Quinn \& Keough 2002). Intake rate was log transformed in order to make the data normally distributed and to homogenize variances. The 3-way interaction was not significant and was therefore removed from the model. Significant effects were further analyzed using simple effects tests.

\section{RESULTS}

\section{Foraging performance in Atlantic cod}

Cod consumption rates increased with prey density in all habitats and for all prey types, but parameter values from non-linear regressions fitted to the observed consumption differed between habitats and prey types (Fig. 1, Table 1). Irrespective of prey type, the highest attack rates, $a$, were obtained in the sand habitat, whereas a was fairly similar between eelgrass and bladderwrack. This was particularly evident for Neomysis integer and Palaemon elegans as prey, showing 5 and 9 times higher attack rates, respectively, in sand habitats. Handling time (h) was prey- but not habitat-dependent, being highest for $P$. elegans and lowest for $N$. integer (approximately 0.041 and $0.026 \mathrm{~s} \mathrm{~J}^{-1}$, respectively; Table 1).

\section{Predator cue experiment}

The rbANOVA showed a significant interaction effect of predator cue and habitat type on cod food consumption $\left(F_{2,71}=7.04, \mathrm{p}=0.002\right)$, revealing a stronger anti-predator response in the sandy habitat (consumption reduced to $22 \%$ ) compared to the other habitats (reduced to $44 \%$, Fig. 2). Consumption was affected by prey density $\left(F_{1,71}=15.8, \mathrm{p}<0.001\right)$, habitat type $\left(F_{2,71}=12.9, \mathrm{p}<0.001\right)$, and predator cue $\left(F_{1,71}=70.9, \mathrm{p}<0.001\right)$, and differed among Atlantic cod individuals $\left(F_{6,71}=2.64, \mathrm{p}=0.023\right)$. Post hoc comparisons of habitat effects revealed a difference only between sand and the 2 complex habitats (Tukey; $\mathrm{p}=$ 0.002 for sand-eelgrass, $\mathrm{p}=0.006$ for sand-bladderwrack, and $\mathrm{p}=0.949$ for eelgrass-bladderwrack comparisons, Fig. 2). There were no significant prey density $\times$ predator cue or prey density $\times$ habitat type interaction terms $\left(\mathrm{rbANOVA}_{i} \mathrm{p}>0.1\right)$ 


\section{Prey density and habitat profitability}

The results from the rbMANOVA showed a significant effect of habitat type on prey density (Wilk's $\lambda=$


Fig. 1. Prey density-dependent consumption rates of juvenile Atlantic cod foraging on 3 different species of crustaceans (symbols) and corresponding type II functional relationships (curves); (a) Neomysis integer (b) Crangon crangon and (c) Palaemon elegans in 3 different habitats; sand ( $\mathbf{\square}$, thin line), Zostera marina ( $\boldsymbol{\Lambda}$, thick line), and Fucus vesiculosus ( $\diamond$, dashed line). Error bars denote $1 \mathrm{SE}$ for 8 replicates for each prey density. The curves were fitted to data using least square non-linear regressions (see 'Materials and methods'). For parameter values see Table 1
0.372, $F_{4,220}=35.2, \mathrm{p}<0.001$; Fig. 3). These effects were significant for both small (rbANOVA, $F_{2,111}=$ $75.9, \mathrm{p}<0.001$ ) and large prey (rbANOVA, $F_{2,111}=$ $8.6 \mathrm{p}<0.001)$. The habitat effect was driven by the density of small prey being significantly lower in sand habitats compared to the vegetation habitats (Tukey, p < 0.001), and large prey density being significantly higher in bladderwrack habitats (Tukey, $\mathrm{p}<0.013)$.

There was a significant interaction effect of habitat type and season on prey density (Wilk's $\lambda=0.828$, $F_{4,220}=5.4, \mathrm{p}<0.001 ;$ Fig. 3). This effect was present for both small and large prey (rbANOVA, $F_{2,111}=4.2$, $\mathrm{p}=0.02$, and $F_{2,111}=8.1 \mathrm{p}<0.001$, respectively), but with different patterns. Small prey had a higher density in September, especially in sand and eelgrass habitats, whereas large prey occurred at lower densi-



Fig. 2. Effects of prey density and chemical cues from a cannibal on the consumption rate (mean $\pm 1 \mathrm{SE}$ ) of juvenile Atlantic cod in 3 different habitats, viz. sand, eelgrass Zostera marina, and bladderwrack Fucus vesiculosus. Prey was the opossum shrimp Neomysis integer in all experiments. Chemical cues from a cannibal (grey bars) decreased consumption rate in all 3 habitats compared with no perceived risk (open bars) and significantly more so in the sand habitat

Table 1. Estimated attack rates and handling times ( $\pm 1 \mathrm{SE})$ from functional response experiments with juvenile Atlantic cod feeding on 3 different crustacean prey in 3 different habitats. Parameter values are estimated using least square nonlinear regression (see 'Materials and methods'). See also Fig. 2

\begin{tabular}{|c|c|c|c|c|c|c|}
\hline \multirow{2}{*}{ Prey type } & \multicolumn{3}{|c|}{ Attack rate $\left(\mathrm{cm}^{2} \mathrm{~s}^{-1}\right)$} & \multicolumn{3}{|c|}{ Handling time $\left(\mathrm{s} \mathrm{J}^{-1}\right)$} \\
\hline & Sand & $\begin{array}{l}\text { Zostera } \\
\text { marina }\end{array}$ & $\begin{array}{c}\text { Fucus } \\
\text { vesiculosus }\end{array}$ & Sand & $\begin{array}{l}\text { Zostera } \\
\text { marina }\end{array}$ & $\begin{array}{c}\text { Fucus } \\
\text { vesiculosus }\end{array}$ \\
\hline Neomysis integer & $57 \pm 22$ & $8.8 \pm 4$ & $13 \pm 7$ & $0.026 \pm 0.005$ & $0.022 \pm 0.01$ & $0.024 \pm 0.01$ \\
\hline Crangon crangon & $1.8 \pm 0.7$ & $0.86 \pm 0.3$ & $1.2 \pm 0.5$ & $0.026 \pm 0.01$ & $0.038 \pm 0.01$ & $0.019 \pm 0.01$ \\
\hline Palaemon elegans & $21 \pm 32$ & $2.4 \pm 2$ & $1.6 \pm 1$ & $0.033 \pm 0.01$ & $0.045 \pm 0.02$ & $0.041 \pm 0.02$ \\
\hline
\end{tabular}





Fig. 3. Habitat-dependent resource density (mean $\pm 1 \mathrm{SE}$ ) and habitat profitability in April and September. (a) Biomass of benthic invertebrates smaller (grey) and larger (white) than $0.1 \mathrm{~g}$ wet weight quantified from sampling with net cages in sand, Zostera marina, or Fucus vesiculosus habitats. (b) Habitat profitability is given as potential consumption rates of juvenile Atlantic cod foraging on a mixture of small and large benthic invertebrates in sand

ties in these habitats in April (Fig. 3). There was no significant main effect of season $(p>0.1)$.

Calculations of habitat profitability, including effects of predation risk, showed that bladderwrack was the most profitable habitat in April, generating a more than 8 times higher consumption rate $\left(17 \mathrm{~J} \mathrm{~s}^{-1}\right)$ than the sand habitat $\left(2 \mathrm{~J} \mathrm{~s}^{-1}\right)$ and twice the consumption rate of the eelgrass habitat ( $8 \mathrm{~J} \mathrm{~s}^{-1}$; Fig. 3). In September, the profitabilities of the eelgrass and bladderwrack habitats were similar $\left(13 \mathrm{~J} \mathrm{~s}^{-1}\right)$ and more than twice as high as the calculated consumption rate in the sand habitat (4 $\mathrm{J} \mathrm{s}^{-1}$; Fig. 3). The cal- culations also showed that cod foraging in sandy habitats were more dependent on large prey compared to the other 2 habitats, in which cod relied more on small prey types (Fig. 3). The inclusion of predation risk in the calculations of habitat profitability did not change the overall pattern, but lowered consumption rates and made the sandy habitat even less profitable compared to the other habitats.

\section{DISCUSSION}

In this study we have quantified the habitat-dependent foraging performance of juvenile cod to derive predictions of habitat profitability in the field. Cod foraging depended on prey density in all of the studied habitats, being more efficient in sand habitats compared to the structurally more complex habitats. Moreover, perceived risk of cannibalism caused a significant reduction in consumption rate in all habitats, with the magnitude of the anti-predator response being more pronounced in the open sandy habitat compared to habitats with macrovegetation. Field observations showed highest resource density in the bladderwrack habitat and lowest in the sand habitat irrespective of season. Our calculations of habitat profitability, combining data from field estimates of resource density and experiments on foraging performance, revealed that habitat degradation might reduce the intake rate of cod to between 12 and $39 \%$ of the intake rate in habitats with vegetation. Our results suggest that this conclusion is robust along gradients of predation risk, at least if predators are not associated with specific habitats. This strengthens the view that the ongoing habitat degradation may have significant ramifications for juvenile cod performance, which ultimately may lower the productivity of entire stocks. Consequently, future and ongoing rebuilding of commercial fish stocks should revise the expectations of stock productivity (and hence harvesting intensity) accordingly.

\section{Foraging performance}

Adaptive foragers should balance costs and benefits and choose the habitat providing the highest net value (Stephen \& Krebs 1986, Gilliam \& Fraser 1987), which ultimately depends on the interplay between predator and prey behaviors. Cod were more efficient foragers in open sand habitats, supporting the general view of cod as an actively searching forager rather than an ambush predator (Laurel \& Brown 2006). This 
was particularly evident for Palaemon elegans prey, which is the more strongly pigmented shrimp species of the two used. The foraging efficiency of cod on Crangon crangon was much lower, despite the fact that C. crangon were of similar size as $P$. elegans. One explanation for this may be the different anti-predator strategies of P. elegans and C. crangon, the former relying on camouflage in the vegetation and the latter burying and hiding within the sandy sediment.

We expected that foraging costs, in terms of predation costs from cannibals, would be habitat specific because the 3 habitats varied in habitat complexity and consequently in their efficiency as refuges (Gotceitas \& Colgan 1989). Juvenile cod are frequently found in complex habitats with eelgrass, macroalgae, or cobble that provide physical protection against predators (Keats et al. 1987, Gotceitas et al. 1997, Linehan et al. 2001). Experimental studies have demonstrated that this choice of habitat is dependent on predator presence; in the absence of predators, cod would prefer less complex and more open habitat (Gotceitas \& Brown 1993, Gotceitas et al. 1995, Fraser et al. 1996). In our experiments, cod were not given any choice of habitat but still modified their foraging behavior as a response to risk. Accordingly, cod reduced their foraging rate more in the sand habitat compared to the more complex habitats both with respect to absolute and relative energetic cost. Hence, this and previous studies clearly suggests that cod will trade more safety against food in what is perceived as riskier environments by altering foraging behavior and/or habitat choice.

\section{Habitat profitability}

We used our experimental results in combination with field estimates of habitat-specific resource densities to predict habitat profitabilities. According to ideal free distribution theory (Fretwell \& Lucas 1970), habitats being used should at equilibrium be equally profitable. In September, habitat-specific intake rates were fairly similar between the eelgrass and bladderwrack habitats despite prey densities being very different. This suggests, first, that cod foraging should avoid the sand habitat altogether, and, second, that cod may drive prey abundances in eelgrass and bladderwrack habitats towards equalization of intake rates. The cod population of the Sound is considered locally distinct and stable with a density and productivity much higher than in surrounding areas (Svedäng et al. 2010a,b). This, together with the fact that cod is the most dominant predator in this marine area, makes it likely that the cod density is high enough to negatively impact prey density.

The small difference in habitat profitability in September between eelgrass and bladderwrack was not repeated in April. This contradicts that Atlantic cod equalize intake rates among habitats. However, biomass of eelgrass varies considerably and reaches a minimum in late winter/early spring, i.e. approximately when the April sampling of benthic invertebrates took place. Hence, eelgrass provides only low structural complexity for benthic invertebrates during this period. In September, eelgrass biomass is at its maximum, and these conditions were replicated in experiments. Although the biomass of bladderwrack also varies seasonally, the magnitude is lower and parts of the stands are always present. Hence, eelgrass and bladderwrack differ fundamentally as potential refuges for benthic invertebrates, which explains the seasonal difference in their profitability to cod. Accounting for a higher search rate of cod in eelgrass in April compared to in September would therefore decrease the profitability differences between the habitats, supporting the view that cod equalize intake rates between habitats and hence have a significant functional role in this ecosystem. Still, there seems to be a significant difference between habitats with or without vegetation, since sand was the least profitable habitat in both seasons.

Previous studies have suggested that the observed use of complex habitats with cobbles or vegetation is a response by cod to risk of predation (Gotceitas \& Brown 1993, Gotceitas et al. 1995). In our study, we showed that even though the risk response was habitat dependent, this did not influence the ranking order of habitats with respect to their overall profitability. Instead, it only increased the absolute difference in profitability between sand and more complex habitats. Increasing risk by introducing an actively foraging predator would likely not change this outcome (Gotceitas et al. 1995), at least if the sand habitat was still perceived as more risky. This illustrates that experimental studies not explicitly accounting for both cost and benefits may make erroneous predictions of the mechanisms generating field patterns. We conclude that both resource availability and risk of predation likely contribute to make more complex habitats more profitable.

Extrapolating the experimental results to natural conditions may be hazardous and we here consider general patterns more robust than specific results. For a generalist predator, prey density in nature is the result of aggregations of prey species rather than one species. Following diet data in the field, we 
therefore considered the total density of mobile epifauna and selected typical prey species in these communities in our experiments. However, a community of prey species will include species that are both more and less available than others, and it is difficult to determine whether our test species are representative species in the prey community. By picking 2 prey types that differed in size, we could at least partly account for habitat differences in the size structure of the prey community. The predicted consumption of large and small prey (Fig. 3) also suggests that these habitat differences are important for both consumption rate and diet selection.

\section{Management implications}

Managing natural resources in a changing world is difficult because the long-term goal may be a moving target. If the environment changes, tools based on conditions of the past may generate poor predictions of the future. This study takes a consumer perspective and provides behavioral decision rules for individuals, applicable to conditions that may arise in the future. Of course, results derived from small-scale experiments should be extrapolated to natural conditions with care, relying more on the patterns of the results than their precise quantities. Still, we believe that mechanistic understanding generated from controlled experiments may guide management options and illuminate what measures mitigating environmental change contribute best to both conservation and fishery yield (Hutchings 2000, Roberts et al. 2001, 2002, Sale et al. 2005). Complementing a general notion with mechanistic relationships, here we showed that complex habitats with bladderwrack or seagrass likely are important nursery grounds for the commercially important cod, providing both resources and shelter from predators. Losses of these habitats may force cod to habitats supporting fewer individuals, thereby diminishing the role of coastal areas as nursery areas. Due to the trophic importance of cod, population effects will likely cascade to lower trophic levels (Casini et al. 2009, Fauchald 2010), ultimately altering the functioning of the entire system (Eriksson et al. 2009). This suggests that major efforts should be directed to preserve such habitats and prevent further habitat loss.

Acknowledgements. We are grateful for the financial support provided by the Swedish Research Council Formas (to A.P. and P.A.N.), Oscar \& Lili Lamm Foundation (to A.P.), and Krapperup Foundation (to A.P.).

\section{LITERATURE CITED}

Baden S, Gullström M, Lunden B, Pihl L, Rosenberg R (2003) Vanishing seagrass (Zostera marina, L.) in Swedish coastal waters. Ambio 32:374-377

Beck MW, Heck KL, Able KW, Childers DL and others (2001) The identification, conservation, and management of estuarine and marine nurseries for fish and invertebrates. Bioscience 51:633-641

$>$ Bjørnstad ON, Fromentin JM, Stenseth NC, Gjøsæter J (1999) Cycles and trends in cod populations. Proc Natl Acad Sci USA 96:5066-5071

Brooks TM, Mittermeir RA, Mittermeir CG, da Fonseca GAB and others (2002) Habitat loss and extinction in the hot spots of biodiversity. Conserv Biol 16:909-923

Casini M, Hjelm J, Molinero JC, Lövgren J and others (2009) Trophic cascades promote threshold-like shifts in pelagic marine ecosystems. Proc Natl Acad Sci USA 106:197-202

> Cloern JE (2001) Our evolving conceptual model of the coastal eutrophication problem. Mar Ecol Prog Ser 210: 223-253

> Eero M, MacKenzie BR, Köster FW, Gislason H (2011) Multidecadal responses of a cod (Gadus morhua) population to human-induced trophic changes, fishing, and climate. Ecol Appl 21:214-226

Eriksson BK, Johansson G, Snoeijs P (1998) Long-term changes in the sublittoral zonation of brown algae in the southern Bothnian Sea. Eur J Phycol 33:241-249

Eriksson BK, Johansson G, Snoeijs P (2002) Long-term changes in the macroalgal vegetation of the inner Gullmar Fjord, Swedish Skagerrak coast. J Phycol 38: 284-296

> Eriksson BK, Ljunggren L, Sandström A, Johansson G and others (2009) Declines in predatory fish promote bloomforming macroalgae. Ecol Appl 19:1975-1988

Fauchald P (2010) Predator-prey reversal: a possible mechanism for ecosystem hysteresis in the North Sea? Ecology 91:2191-2197

Frank KT, Petrie B, Shackell NL, Leggett WC (2005) Trophic cascades in a formerly cod-dominated ecosystem. Science 308:1621-1623

> Fraser S, Gotceitas V, Brown JA (1996) Interactions between age-classes of Atlantic cod and their distribution among bottom substrates. Can J Fish Aquat Sci 53:305-314

Fretwell SD, Lucas HL Jr (1970) On territorial behavior and other factors influencing habitat distribution in birds. I. Theoretical development. Acta Biotheor 19:136-156

Fryxell JM, Lundberg P (1998) Individual behavior and community dynamics. Chapman \& Hall, London

Gibson RN (1994) Impact of habitat quality and quantity on the recruitment of juvenile flatfishes. Neth J Sea Res 32: 191-206

Gilliam JF, Fraser DF (1987) Habitat selection under predation hazard: a test of a model with foraging minnows. Ecology 68:1856-1862

Gotceitas V, Brown JA (1993) Substrate selection by juvenile Atlantic cod (Gadus morhua): effects of predation risk. Oecologia 93:31-37

Gotceitas V, Colgan P (1989) Predator foraging success and habitat complexity: quantitative test of the threshold hypothesis. Oecologia 80:158-166

Gotceitas V, Fraser S, Brown JA (1995) Habitat use by juvenile cod (Gadus morhua) in the presence of an actively foraging and non-foraging predator. Mar Biol 123: 421-430 
Gotceitas V, Fraser S, Brown JA (1997) Use of eelgrass beds (Zostera marina) by juvenile Atlantic cod (Gadus morhua). Can J Fish Aquat Sci 54:1306-1319

Hansson S, Hjerne O, Harvey C, Kitchell JF, Cox SP, Essington TE (2007) Managing Baltic Sea fisheries under contrasting production and predation regimes: ecosystem model analyses. Ambio 36:265-271

Holling CS (1959) Some characteristics of simple types of predation and parasitism. Can Entomol 91:385-398

> Hüssy K, St John MA, Böttcher U (1997) Food resource utilization by juvenile Baltic cod Gadus morhua: a mechanism potentially influencing recruitment success at the demersal juvenile stage? Mar Ecol Prog Ser 155:199-208

Hutchings JA (2000) Collapse and recovery of marine fishes. Nature 406:882-885

Isaksson I, Pihl L, Vanmontfrans J (1994) Eutrophicationrelated changes in macrovegetation and foraging of young cod (Gadus morhua) - a mesocosm experiment. J Exp Mar Biol Ecol 177:203-217

> Jackson JBC, Kirby MX, Berger WH, Bjorndal KA and others (2001) Historical overfishing and the recent collapse of coastal ecosystems. Science 293:629-637

> Kautsky N, Kautsky H, Kautsky U, Wärn M (1986) Decreased depth penetration of Fucus vesiculosus (L.) since the 1940's indicates eutrophication of the Baltic Sea. Mar Ecol Prog Ser 28:1-8

- Keats DW, Steele DH, South GR (1987) The role of fleshy macroalgae in the ecology of juvenile cod (Gadus morhua L.) in inshore waters off eastern Newfoundland. Can J Zool 65:49-53

Lambert Y (2011) Environmental and fishing limitations to the rebuilding of the northern Gulf of St. Lawrence cod stock (Gadus morhua). Can J Fish Aquat Sci 68:618-631

Laurel BJ, Brown JA (2006) Influence of cruising and ambush predators on 3-dimensional habitat use in age 0 juvenile Atlantic cod Gadus morhua. J Exp Mar Biol Ecol 329:34-46

Linehan JE, Gregory RS, Schneider DC (2001) Predation risk of age 0 cod (Gadus morhua) relative to depth and substrate in coastal waters. J Exp Mar Biol Ecol 263:25-44

Lotze HK, Lenihan HS, Bourque BJ, Bradbury RH and others (2006) Depletion, degradation, and recovery potential of estuaries and coastal seas. Science 312:1806-1809

Mathis A, Smith RJF (1993) Chemical alarm signals increase the survival time of fathead minnows (Pimephales promelas) during encounters with northern pike (ESox lucius). Behav Ecol 4:260-265

Olsson P (2005) Marine field studies in Öresund 2005 - Eelgrass. Toxicon, Landskrona (in Swedish)

Orth RJ, Carruthers TJB, Dennison WC, Duarte CM and others (2006) A global crisis for seagrass ecosystems. Bioscience 56:987-996

Österblom H, Hansson S, Larsson U, Hjerne O, Wulff F, Elmgren R, Folke C (2007) Human-induced trophic cascades and ecological regime shifts in the Baltic Sea. Ecosys-

Editorial responsibility: Jana Davis,

Annapolis, Maryland, USA tems 10:877-889

Pauly D, Christensen V, Guénette S, Pitcher TJ and others (2002) Towards sustainability in world fisheries. Nature 418:689-695

> Pettersson LB, Nilsson PA, Brönmark C (2000) Predator recognition and defense strategies in crucian carp, Carassius carassius. Oikos 88:200-212

Pihl L, Baden S, Kautsky N, Rönnback P, Söderqvist T, Troell M, Wennhage H (2006) Shift in fish assemblage structure due to loss of seagrass Zostera marina habitats in Sweden. Estuar Coast Shelf Sci 67:123-132

Quinn GP, Keough MJ (2002) Experimental design and data analysis for biologists. Cambridge University Press, Cambridge

> Roberts CM, Bohnsack JA, Gell FR, Hawkins JP, Goodridge $R$ (2001) Effects of marine reserves on adjacent fisheries. Science 294:1920-1923

Roberts CM, Bohnsack JA, Gell FR, Hawkins JP, Goodridge $\mathrm{R}$ (2002) Marine reserves and fisheries management. Science 295:1233-1235

Rönnbäck P, Kautsky N, Pihl L, Troell M, Söderqvist T, Wennhage H (2007) Ecosystem goods and services from Swedish coastal habitats: identification, valuation, and implications of ecosystem shifts. Ambio 36:534-544

Sale PF, Cowen RK, Danilowicz BS, Jones GP and others (2005) Critical science gaps impede use of no-take fishery reserves. Trends Ecol Evol 20:74-80

> Short FT, Wyllie-Echeverria S (1996) Natural and humaninduced disturbance of seagrasses. Environ Conserv 23: 17-27

Stephen DW, Krebs JR (1986) Foraging theory. Princeton University Press, Princeton, NJ

> Svedäng H, Stål J, Cardinale M (2010a) Consequences of subpopulation structure on fisheries management: cod (Gadus morhua) in the Kattegat and Öresund (North Sea). Rev Fish Sci 18:139-150

> Svedäng H, André C, Jonsson P, Elfman M, Limburg K (2010b) Homing behaviour and otolith chemistry suggest fine-scale sub-population structure within a genetically homogenous Atlantic cod population. Environ Biol Fishes 89:383-397

Tupper M, Boutilier RG (1995) Effects of habitat on settlement, growth, and postsettlement survival of Atlantic cod (Gadus morhua). Can J Fish Aquat Sci 52:1834-1841

> Vogt H, Schramm W (1991) Conspicuous decline of Fucus in Kiel Bay (Western Baltic): What are the causes? Mar Ecol Prog Ser 69:189-194

> Waycott M, Duarte CM, Carruthers TJB, Orth RJ and others (2009) Accelerating loss of seagrass across the globe threatens coastal ecosystems. Proc Natl Acad Sci USA 106:12377-12381

Wikström SA, Kautsky L (2007) Structure and diversity of invertebrate communities in the presence and absence of canopy-forming Fucus vesiculosus in the Baltic Sea. Estuar Coast Shelf Sci 72:168-176

Submitted: October 25, 2011; Accepted: March 3, 2012 Proofs received from author(s): May 28, 2012 